\title{
CEsifo WORKING

\section{Credit Market Imperfection, Lack of Entrepreneurs and Capital Outflow from a Developing Economy}

Sugata Marjit, Suryaprakash Mishra 


\section{Impressum:}

CESifo Working Papers

ISSN 2364-1428 (electronic version)

Publisher and distributor: Munich Society for the Promotion of Economic Research - CESifo

$\mathrm{GmbH}$

The international platform of Ludwigs-Maximilians University's Center for Economic Studies and the ifo Institute

Poschingerstr. 5, 81679 Munich, Germany

Telephone +49 (0)89 2180-2740, Telefax+49 (0)89 2180-17845, email office@cesifo.de

Editor: Clemens Fuest

https://www.cesifo.org/en/wp

An electronic version of the paper may be downloaded

- from the SSRN website: www.SSRN.com

- from the RePEc website: $\quad$ www.RePEc.org

- from the CESifo website: https://www.cesifo.org/en/wp 


\title{
Credit Market Imperfection, Lack of Entrepreneurs and Capital Outflow from a Developing Economy
}

\begin{abstract}
This paper explores the impact of credit market on the entrepreneurs and demand for credit in a credit constrained economy and the resultant impact on the capital flows. In standard trade models the capital flows across countries are explained as a result of the rate of return differentials due to presence/absence of capital among the countries whereby capital flows from the capital rich countries to capital poor countries. We show that the rate of return differentials could arise due to presence/absence of entrepreneurs, i.e., low price of capital in autarky may reflect lack of demand for credit due to scarcity of entrepreneurs and not capital abundance and eventually may lead to capital outflow from a capital scarce country. This is a different way of echoing the sentiment of the well-known "Lucas Paradox" which suggests that capital might flow from the poor to the rich countries. We also show the possibility of trade and capital flow being complements and not substitutes, as is usual in standard models.
\end{abstract}

JEL-Codes: F210, F360, D630, G210.

Keywords: credit market imperfection, credit rationing, redistribution, entrepreneurs, capital flows.

\author{
Sugata Marjit \\ Indian Institute of Foreign Trade \\ Calcutta / India \\ marjit@gmail.com
}

\author{
Suryaprakash Mishra \\ National Law University \\ New Delhi / India \\ misra.suryaprakash@gmail.com
}

This paper has benefitted from seminar presentations at and/or academic visits to CSSSC, Indian Institute of Management, Ahmedabad, IGIDR, Mumbai, Washington University, St. Luis, Australian National University, IMF, Universities of Kobe and Tokyo. I am indebted to Rajat Acharyya, Subhayu Bandopadhyay, Aninda Chakraborty, Marcel Thum, Heinrich Ursprung, Prasada Rao, Arye Hillman, Eden Eu, Lei Yang, Reza Oladi and Hamid Beladi. The usual disclaimer applies. 


\section{Introduction}

The purpose of this paper is to explore as to how credit market imperfection may affect entrepreneurship and direction of capital flows in an economy with credit rationing. In particular, we would show that low price of capital or asset in autarky may reflect the lack of demand for credit due to scarcity of entrepreneurs and not necessarily due to capital abundance and eventually may lead to capital outflow from a capital scarce country. This also leads to a situation where trade and capital flows become complements, and capital may flow out of a relatively poor to rich country in spite of the poor country being capital scarce.

This paper contributes to the theoretical literature on trade and capital flows under credit market imperfection which itself is not voluminous. Jones and Marjit (2001), Wynne (2005), Antras and Caballero (2009), Von Hagen and Zhang (2014), Matsuyama (2007), Manova and $\mathrm{Yu}$ (2014) etc. discuss various aspects of related problem. But none of them explores the role of wealth distribution in capital flows through our channel whereby lack of entrepreneurs drives away capital from a capital scarce country. Von Hagen and Zhang (2014) in a macro set up discussed the possibility of ambiguous capital flows but our mechanism is absent there. The basic point of our paper is that the lack of entrepreneurship magnifies the problem of credit constraint by driving capital away. ${ }^{1}$

Lucas (1990) describes a situation where capital flows from poor to rich countries since real rate differential includes positive externality effect of human capital in the North. Alfaro et al. (2008) in an empirical paper spanning 1970-2000 argues that capital does flow in and out of poor coutries with poor institutional quality being the main explanation for outflow. This is an empirical backing for our paper. Antras and Caballero (2009) shows that with financial frictions trade and capital flow can be complements even if trade is driven by factor abundance and shows that such an impact has to do with trade improving the environment for capital inflow. Ours is a very different approach, though we show that capital can flow from poor to rich countries with a reinterpretation of Lucas (1990) and trade and capital flow may be complements. Our basic point is that redistribution may be inefficient and thus hurting the local demand for credit or capital, lowering the local return, as in the price of the asset and hence leading to capital outflow. Thus re/distribution and the im/perfection lie in the core of

\footnotetext{
${ }^{1}$ Wynne (2005), Oechslin (2010), Sato (1996) discuss the implications of credit constraint on trade. But they do not focus on the problem of this paper. Peters and Schnitzer (2015) and Bandopadhyay, Marjit and Yang (2014) have analysed the role of finance in growth, and convergence and outsourcing and unemployment respectively. Other interesting papers that the reader may have a look at are Gal-or and Zeria (1993), Banerjee and Newman (1993) and Galor and Moav (2004). However, the topic in hand is quite different.
} 
our analysis. The particular mechanism by which lack of entrepreneurship affects the local return to capital has not been focussed in the existing literature as well as its consequence on pattern of trade and capital flows.

This paper is mainly related to Antras and Caballero (2009), Lucas (1990) and Von Hagen and Zhang (2014). We consider credit market friction in the form of credit rationing as in Antras and Caballero (2009) and bring in explicitly the role of wealth distribution to show that trade and capital flows can be complements, but like Lucas (1990) and Von Hagen and Zhang (2014)we get the result that capital may flow from poor to a rich country even when capital is scarce in the poor country. But here the scarcity of capital is due to lack of demand for credit due to shortage of entrepreneurs which may be caused by egalitarian redistribution. While efficient egalitarian distribution yields the conventional results, inefficient distribution generates counter intuitive outcomes by affecting demand for capital or credit. This key point is the novelty of our paper. Two exactly similar countries but with different wealth distribution can engage in trade and capital flows. In our model an egalitarian redistribution in capital scarce country can drive capital away due to lack of demand effect though the country may import capital intensive good.

The structure of the rest of the paper is as follows. The second section describes the general equilibrium of a credit rationed economy in terms of a Ricardian continuum model. The third section analyses trade and capital flows with different patterns of redistribution in a competitive model. The fourth section deals with the case of imperfect product market. The last section concludes.

\section{The Model}

\section{(a). Firms and Workers}

We consider two sectors producing $X$ and $Y$ respectively. $X$ needs credit as well as labor while $Y$ needs only labor. Production of both $(X$ and $Y$ ) requires one unit of labor per unit of output. An agent can be a worker or an entrepreneur in $X$. As worker she gets the same wage as in $Y$. As an entrepreneur she hires workers, employs capital or credit which she may borrow from the bank and compares her opportunity cost of not being in $Y$. 
Workers/Potential entrepreneurs are distributed in a continuum with assets $k(z), k^{\prime}>$ $0, \in[0,1] . Y$ is the numeraire good. Opportunity cost of not being in $Y$ is given by,

$$
c(z)=r+k(z) r=r(1+k(z)
$$

Equation (1) states that workers can invest their wage income and the asset to obtain rate of return $r . r$ is determined globally and is exogenous to the model. We treat $R=(1+r)$. Profit of the $z^{\text {th }}$ entrepreneur in $X$ is given by,

$$
\pi(z)=P[B(z)+k(z)]-B(z) R-k(z) r
$$

$B(z)$ denotes borrowing; $R$ (the borrowing rate) $>r$ (the deposit rate). Competitive product markets imply that the individual firm takes $P$ as given.

An agent would be an entrepreneur in $X$ iff,

$$
(P-R) B(z)+(P-r) k(z) \geq r
$$

Note that $P>R>r$, otherwise $B(z)=0$. Also, individual demand for $B(z)$ at a given $P$ is unbounded. Since firms are competitive, they would like to sell as much as they can.

\section{(b). Banks}

Banks are competitive in the sense that they face a constant deposit rate $r$ and charge a premium on $r$ to cover the intermediation costs. Competitive banking with intermediation cost implies $R=\mu r ; \mu=$ intermediation cost $>1$. But as $R>r$, external finance is more costly than own resources.

Banks worry about default [Aghion and Benerjee (2005)]. No default incentive constraint would be as follows.

$$
\pi(z) \geq P[B(z)+k(z)]-k(z) r-q \theta[k(z)+B(z)]
$$

Or, 


$$
B(z) \leq \frac{q \theta}{R-q \theta} k(z)
$$

where $q$ is the probability that the defaulter can be punished and if punished $\theta$ fraction of the total assets can be approximated by the bank. ${ }^{2}$

We now derive the supply side of the model. From (3),

$$
k(\tilde{z})=\frac{r}{(P-R) \frac{q \theta}{R-q \theta}+(P-r)}=\frac{r}{(P-\mu r) \frac{q \theta}{\mu r-q \theta}+(P-r)}=\phi(r, P)
$$

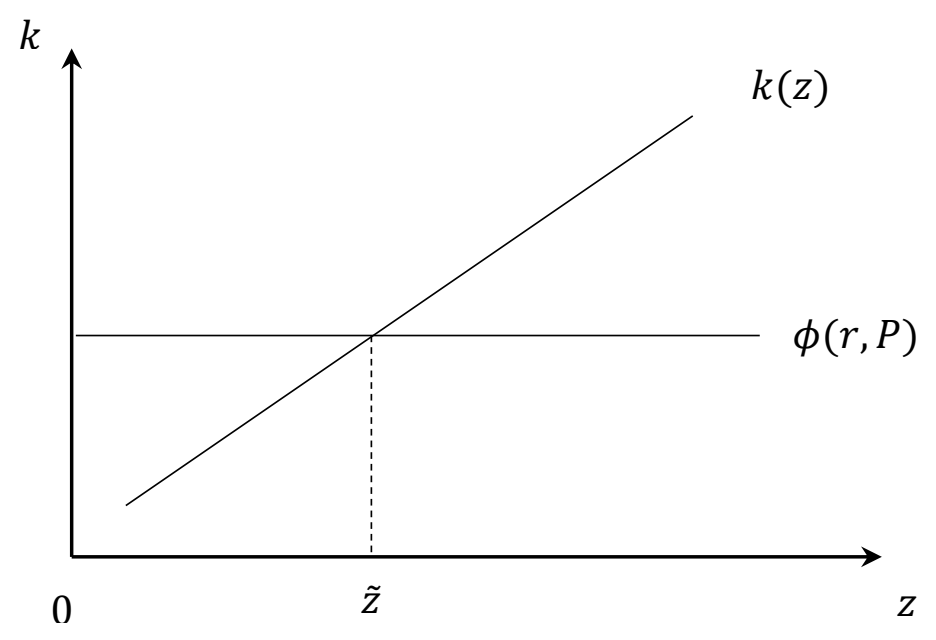

Figure 1: Equilibrium range of workers/entrepreneurs

If there is an interior equilibrium then $\forall z \geq \tilde{z}$, workers become entrepreneurs and $\forall z<\tilde{z}$, they choose to remain as workers (see figure (1)). Note that our result here is consistent with the empirical finding of Rajan and Zingales (1998). If the banks can better audit and impose greater penalty on defaulters, each will get raise in terms of maximum amount of loan. This will expand the set of entrepreneurs leading to higher output of the credit-intensive good.

Total Output is determined as follows,

$$
X(\tilde{z})=\int_{\tilde{z}}^{1} X(z) d z=\left(1+\frac{q \theta}{\mu r-q \theta}\right) \int_{\tilde{z}(P)}^{1} k(z) d z
$$

\footnotetext{
${ }^{2}$ Better monitoring by banks would ensure availability of more credit and hence encourage entrepreneurship and hence enhance the demand for credit and thereby the price of capital.
} 


$$
\frac{\delta X}{\delta P}>0 \text { as } \tilde{z}^{\prime}<0
$$

$$
X(\tilde{z})+Y=\tilde{z}
$$

or,

$$
\frac{X(\tilde{z})}{Y}=\left(\frac{X(\tilde{z})}{\tilde{z}-X(\tilde{z})}\right)
$$

Equation (9) defines the relative supply of $X$ as a function of $P$. As $P$ increases there are more entrepreneurs and less workers, expanding $X$ and contracting $Y$. We now close the model with a simple assumption of homothetic demand. Homothetic demand implies,

$$
\frac{X^{D}}{Y^{D}}=f(P) ; f^{\prime}<0
$$

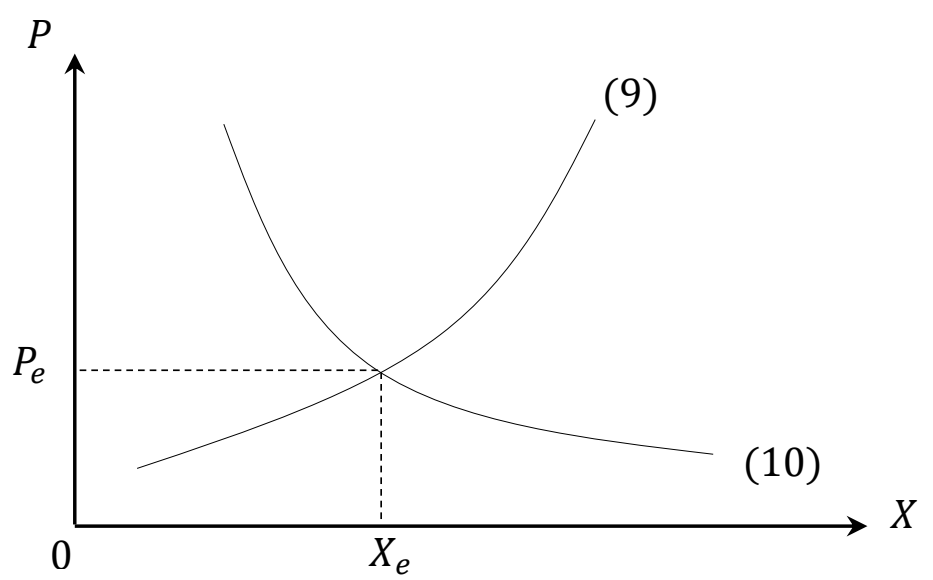

Figure 2: Commodity Market Equilibrium

By setting (9) equal to (10), we determine the equilibrium relative price of $X, P_{e}$, in autarky, as is shown in figure (2).

Therefore,

$$
k\left(\tilde{z}_{e}\right)=\phi(r, P)
$$

In equilibrium we have $\tilde{z}_{e}$ workers and $\left(1-\tilde{z}_{e}\right)$ entrepreneurs. $P_{e}$ denotes the autarkic equilibrium.

\footnotetext{
${ }^{3}$ As labor needs to be fully employed.
} 


\section{Credit Market Equilibrium}

With the assumption that competitive banking has to be the same for all the borrowers, each bank charges an intermediation cost $\mu>1$ over and above $r$.

Total supply of credit is given by $K^{s}=\int_{0}^{\tilde{z}} k(z) d z$ when $\tilde{z}$ is the cut-off point.

Similarly, demand for credit is given by $K^{d}=\int_{\tilde{z}}^{1}\left[\frac{q \theta}{\mu r-q \theta}\right] k(z) d z$. Also $\tilde{z}$ is determined by (6).

The credit market clearing condition is as follows.

$$
\begin{gathered}
\left(\frac{q \theta}{\mu r-q \theta}\right) \int_{\tilde{Z}(r)}^{1} k(z) d z=\int_{0}^{\tilde{z}(r)} k(z) d z \\
k(\tilde{z})=\frac{1}{\left(\frac{P}{r}-\mu\right)\left(\frac{q \theta}{\mu r-q \theta}\right)+\frac{P}{r}-1}
\end{gathered}
$$

Hence, as $k^{\prime}>0, \quad \tilde{z}^{\prime}(r)>0$

Equations (12) and (13) imply that LHS in (12) is downward sloping and RHS in (12) is upward rising as shown in figure 3.

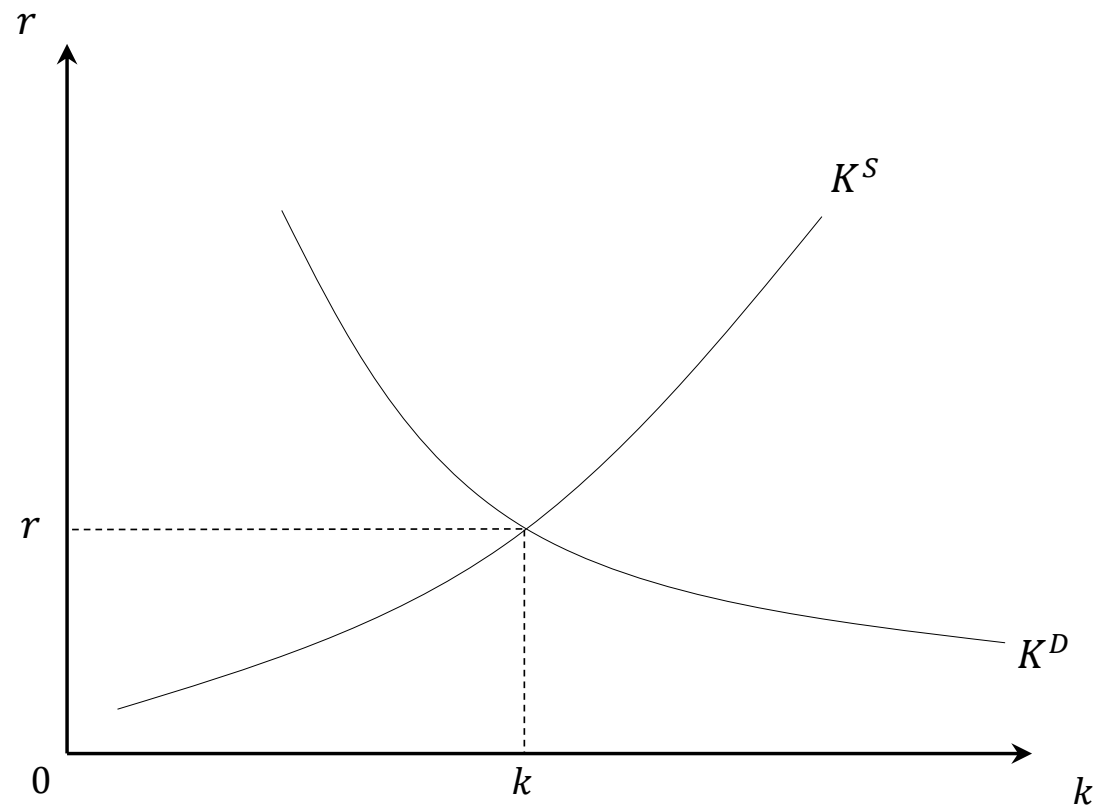

Figure 3: Credit Market Equilibrium 


\section{General Equilibrium}

From (13) we know that as $P$ increases, $\tilde{z}$ must go down, shifting the demand (for credit) up and supply (of credit) down and thus leading to a rise in $r$. This defines the locus of $(P, r)$ as $K K$ in figure 4 . The commodity market equilibrium is also affected by changes in $r$. In figure 2, higher $r$ will reduce supply of $X$ by raising $\tilde{z}$ and will increase $P$. This is defined as the locus CC in figure 4.

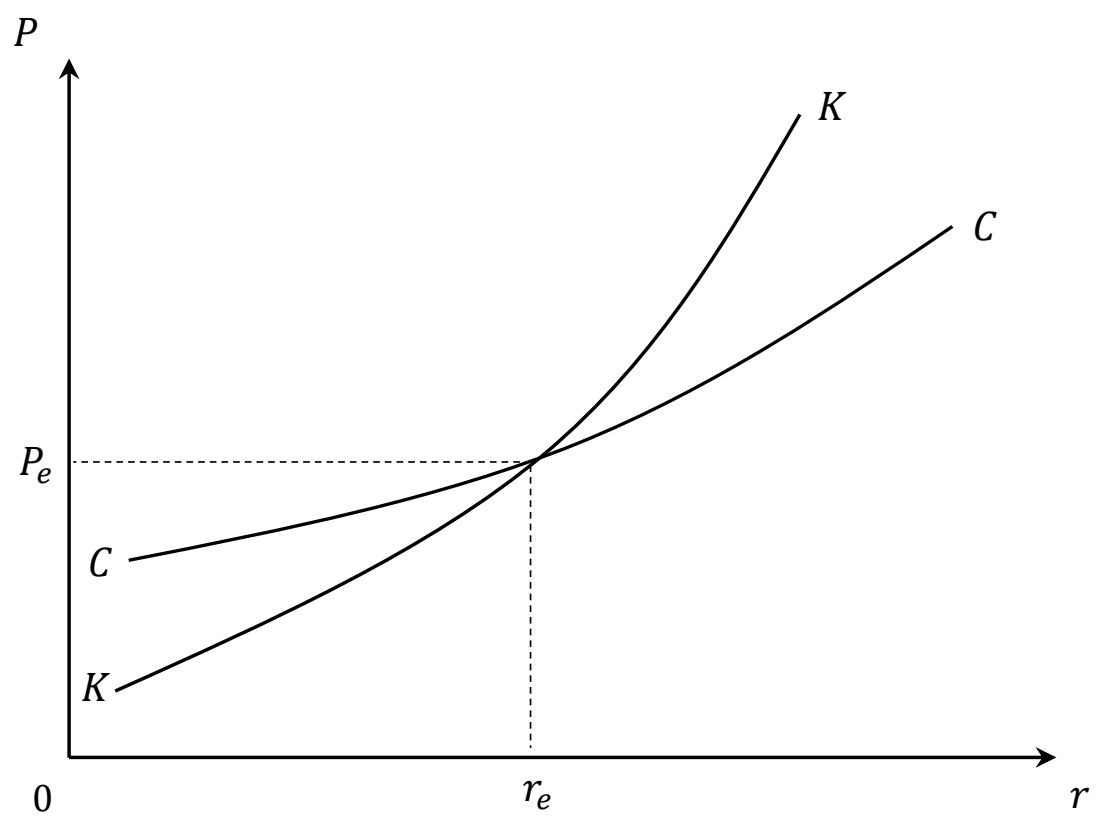

Figure 4: General Equilibrium under autarky

$P\left(P_{e}, r_{e}\right)$ represent the general equilibrium solution of the system. They in turn determine $\tilde{z}, X$ and $Y$. Note that adjusting along $C C$ and adjusting along $K K$ guarantees stability of equilibrium.

\section{Distribution, Trade and Capital Flows}

Consider the impact of an egalitarian distribution on autarkic equilibrium. The distribution takes the form of redistributing wealth from existing entrepreneurs to nonentrepreneurs such that total amount of wealth remains the same and we can study pure redistribution effect. Thus, we can compare two countries, same in every respect, but one having a more equal while the other having a more skewed distribution. One basic point that we wish to suggest is that such redistribution may or may not increase output of $X$, although 
the redistribution allows some of the existing workers to borrow from the bank and become entrepreneurs. When output of $X$ decreases we call it inefficient redistribution. Figure 5(a) is an example of inefficient redistribution whereas $5(\mathrm{~b})$ points towards the possibility of efficient redistribution.

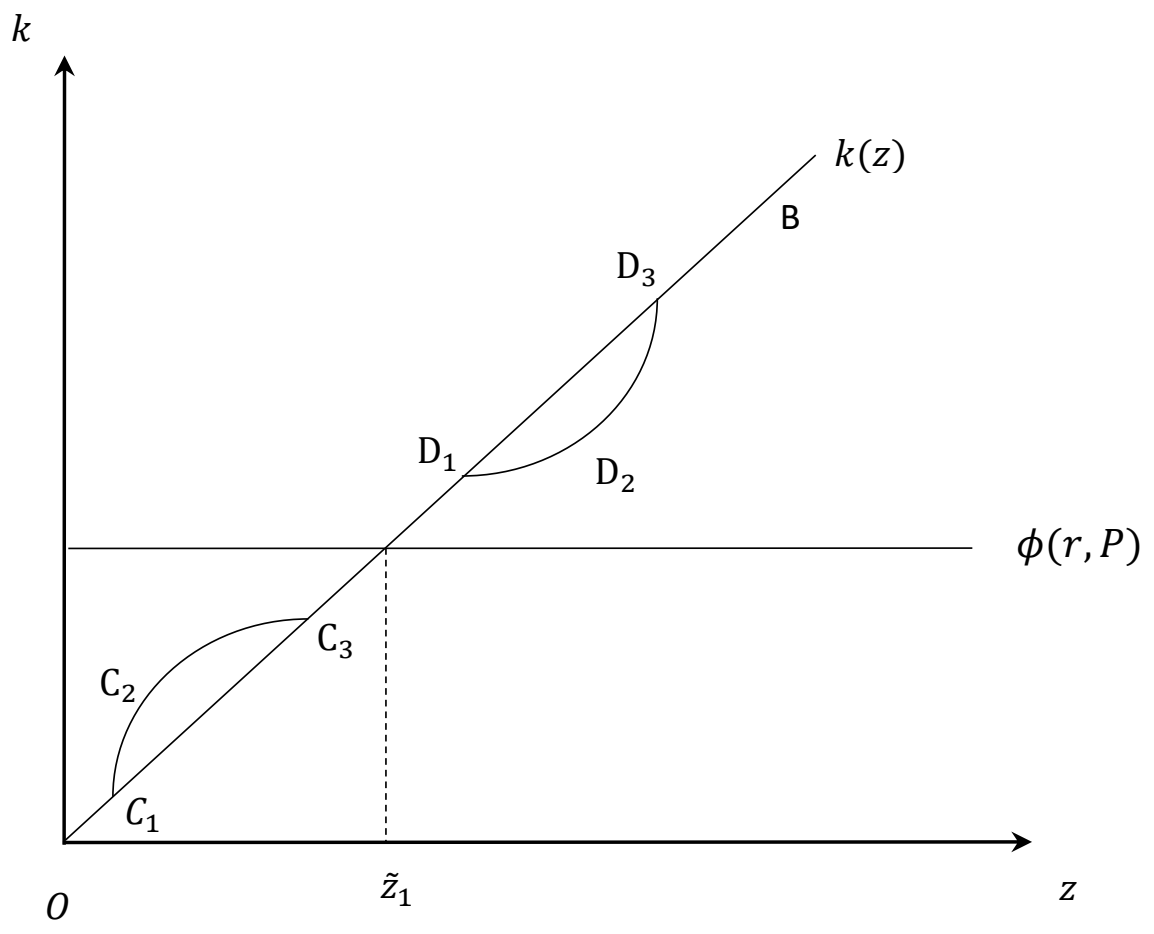

Figure 5 (a): Inefficient Redistribution

Both in 5(a) and 5(b) area $D_{1} D_{2} D_{3}=$ area $C_{1} C_{2} C_{3}$ such that old and new distribution $O C_{1} C_{3} D_{1} D_{3} B$ and $O C_{1} C_{2} C_{3} D_{1} D_{2} D_{3} B$ have the same aggregate amount of wealth, so that the area $D_{1} D_{2} D_{3}=$ area $C_{1} C_{2} C_{3}$. 


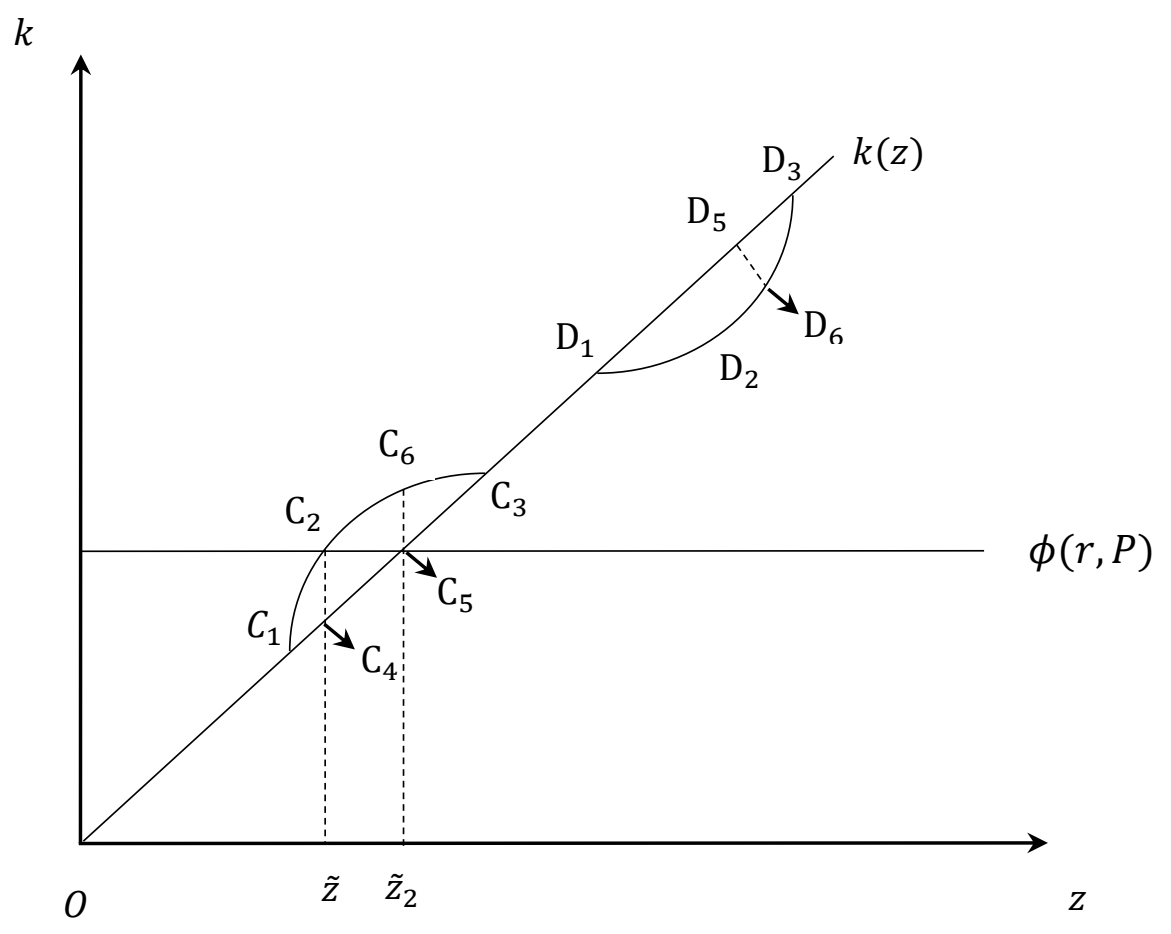

Figure 5 (b): Efficient Redistribution

Note that in figure 5(b) out of $C_{1} C_{2} C_{3}$, area $C_{5} C_{6} C_{3}$ goes to existing entrepreneurs and added to production of $\mathrm{X}$ compensating part of the loss given by area $D_{3} D_{4} D_{5}$. Area $C_{1} C_{2} C_{4}$ is lost because that won't be used as productive capital in $X$. But now as new entrepreneurs come in $\left[\tilde{z}_{2}-\tilde{z}\right]$, the entire capital $\left(\tilde{z} \tilde{z}_{2} C_{2} C_{6}\right)$ will be engaged in production of $X$, not only $\left(C_{2} C_{4} C_{5} C_{6}\right)$. Hence it is the comparison between $\left(D_{1} D_{4} D_{5}\right)$ and $\left(\tilde{z} \tilde{z}_{2} C_{2} C_{6}\right)$. That will determine whether at given $(P, r) X$ will rise. A redistribution described by figure 5(a) will surely curtail output of $X$.

It is clear that figure 5(b) points towards more skewed redistribution than in 5(a). In other words more egalitarian redistribution increases the possibility of lower usage of credit in sector $X$, given the same aggregate $K, r$ and $P$. Of course, in equilibrium we shall have different equilibrating values of $r$ and $P$. For subsequent analysis we consider two economies, other things remaining the same, one is characterised by a distribution such as in 5(a) and the benchmark the less egalitarian one given by the initial linear $k(z)$ line.

Let us now look at the resultant autarkic general equilibrium outcome for more egalitarian economy. It is clear that at given $r$, lower production of $X$ relative to the benchmark will raise $P$ at a given $r$, shifting up $C_{1} C_{1}$ to $C_{2} C_{2}$. At the same time demand for entrepreneurial 
capital will reduce $r$ at a given $P$, shifting $K_{1} K_{1}$ to the left as $K_{2} K_{2}$. This is described in figure 6. Thus compared to the benchmark equilibrium $\left(P_{1}, r_{1}\right)$ we have $P_{2}>P_{1}$ and $r_{2}<r_{1}$. Note that with inefficient redistribution $P$ may be higher, as in autarky we have lower quantity of $X$ being produced in equilibrium.

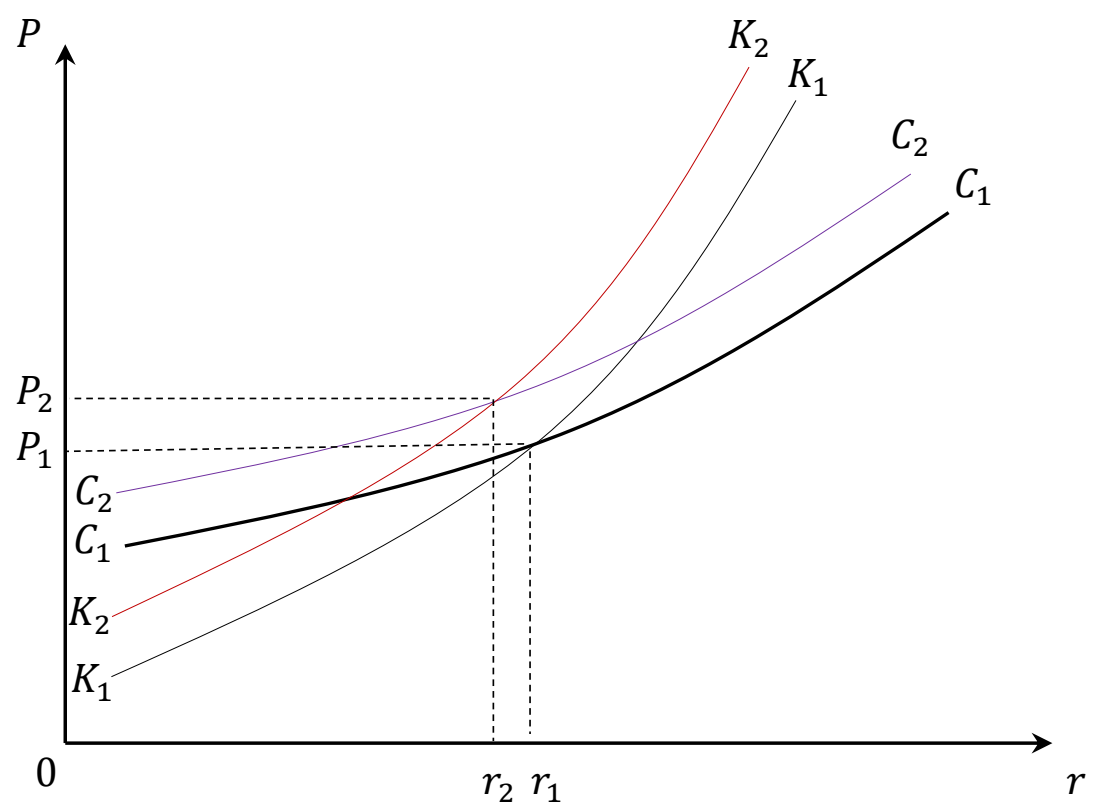

Figure 6: Egalitarian Redistribution and the General Equilibrium under autarky

We now present the mechanism to guarantee $P_{1}>P_{2}$ and $r_{1}<r_{2}$.

Proposition 1: There will always be an equilibrium where more egalitarian economy relative to the benchmark economy will import $X$ and export capital.

Proof: Let us define two functions capturing $C C$ and $K K$.

$$
\begin{aligned}
& C C \rightarrow P=\phi\left(\begin{array}{cc}
r & \eta \\
+, & +
\end{array}\right) \\
& K K \rightarrow r=\psi\left(\begin{array}{cc}
P & \eta \\
+, & -
\end{array}\right)
\end{aligned}
$$

where $\eta$ measures the degree of egalitarian distribution which given $(P, r)$ reduces production of $X$ and increases $P$ and reduces demand for $K$ and reduces $r$, in commodity and capital market respectively.

$$
\frac{d P}{d \eta}>0 \text { and } \frac{d r}{d \eta}<0 \text { iff } \phi_{r}<\phi_{\eta}<\frac{1}{\psi_{P}}
$$


and $1-\phi_{r} \psi_{P}>0$ due to stability condition. Hence $\exists \phi_{\eta}$ satisfying (16). $\boldsymbol{Q E D}$. [See appendix]

If capital is not allowed to move beyond national boundary and $X$ is imported, $P$ will fall in free trade equilibrium. This will further reduce number of entrepreneurs and demand for capital pushing $r_{2}$ lower in the importing country. As a mirror image $r_{1}$ will move up in the benchmark nation. Thus $\left(r_{1}-r_{2}\right)$ will increase, increasing the possibility of capital outflow. Thus, trade in goods and capital will be complements.

It is important to note that if instead of distributional difference capital was scarce in country $1, X$ would be lower in autarky and $P$ higher. However, in the capital market low supply (scarcity) of capital will push up $r_{1}$ above $r_{2}$. We shall have a standard outcome where given a chance capital will flow in, and not flow out. Trade and capital flow will be substitutes as greater inflow of capital will reduce the necessity to import $X$. This is the conventional wisdom and greater inflow of capital will restrict trade in $X$.

Proposition 2: Trade and capital flow will be complements in an equilibrium described by Proposition 1.

Proof: See the discussion above. $\boldsymbol{Q E D}$.

If an economy is poor relative to the benchmark economy, having less wealth and also has a more egalitarian distribution that hurts production of $X$ there will be two offsetting effects on $r$. Scarcity of capital will push it up, while the lack of entrepreneurs will push it down. The final effect on $r$ would depend upon the net of the above two effects. When the "lack of the entrepreneurs" effect would be dominant, one may have a situation where a capital scarce economy will export capital, reflecting some sort of a Lucas Paradox whereby capital will flow from the South to the North.

One issue that is significant here is the behaviour of $\phi_{\eta}$, i.e., how far will a change in distribution will affect $P$ given $r$. This will clearly depend on the elasticity of demand for $X$. More inelastic is the demand, $P$ will rise more and hence $\phi_{\eta}$ will have a higher value. This will tend to raise $P$ in the ultimate equilibrium. But if elasticity of demand is low it will also lead to a greater impact of higher $r$ on $P$. Thus, $\phi_{r}$ will also tend to be high. Hence, lower elasticity will not necessarily work towards a lower $\phi_{r}$ as denoted by (8A). Thus, capital may still have a higher rate of return in autarky. As higher $P$ will not raise $r$ by that much if the number of new entrepreneurs is low reflecting a skewed initial asset distribution. Thus $\psi_{p}$ will have a low value and it is more likely that (8A) will hold given $\phi_{\eta}$. 


\section{Product Market Imperfection and Capital Flight}

So far we have assumed that all firms are small and given $P>R$, have infinite demand for credit or capital. Thus rationed amount of credit determines the activity level of entrepreneurs. One can easily consider the case where firms are not atomistic and they set prices to maximise profits. For lower degree of competition firms will set higher price and lower output and credit constraint may not be binding. In that case there will be excess supply of credit and equivalent amount of collateral which could be transferred to relatively poor nonproducers, increasing $X$ and demand for credit leading to higher $r$, moving more towards a situation where the economy can have more entrepreneurs. If capital flow is allowed capital will flow into the country with more egalitarian distribution. Note that without explicit redistribution, lower degree of competition will increase $P$, encourage entrepreneurs and increase $r$. More competition will push $P$ down. But $P$ will remain high relative to a situation with higher degree of competition. However, lower degree of competition will tend to raise $P$ as well as $r$ and as credit demand falls short of credit supply, further redistribution will increase $r$ further by pushing up the demand for credit, limiting the possibility of capital flight. Therefore, the inefficiency in redistribution will be countered by product market imperfection. The idea of an imperfect product market replaces the demand-supply equality with the profit maximising condition, i.e.,

$$
P=\frac{r \mu}{1-\frac{1}{\epsilon}}
$$

where $\epsilon$ is the elasticity of demand. We treat $\epsilon$ as an indicator of degree of competition in the sense of how important is the product. Lower $\epsilon$ will be assumed to imply lower degree of competition. (9A) is derived from the following process.

For given $\tilde{z}$, any $z \in[\tilde{z}, 1]$, tries to determine its optimal output by maximizing profits. Such $x(z) \leq k(z)(1+\beta)$, i.e., profit maximizing $x(z)$ falls short of total available capital or it is not rationed. We assume that this is true for all $z \in[\tilde{z}, 1]$. As $\epsilon \rightarrow \alpha$, we get back to the competitive equilibrium we have dealt with earlier. Given $r$ and $\epsilon, P$ is determined from (17). This is the commodity market story where output for each firm is now chosen keeping in view the price impact.

Given any $P, \tilde{z}(r, P)$, credit market clears with some $r$ on $K K$ curve remaining the same. But $C C$ is a linear relationship between $P$ and $r$ given $\epsilon$ (figure 7). 


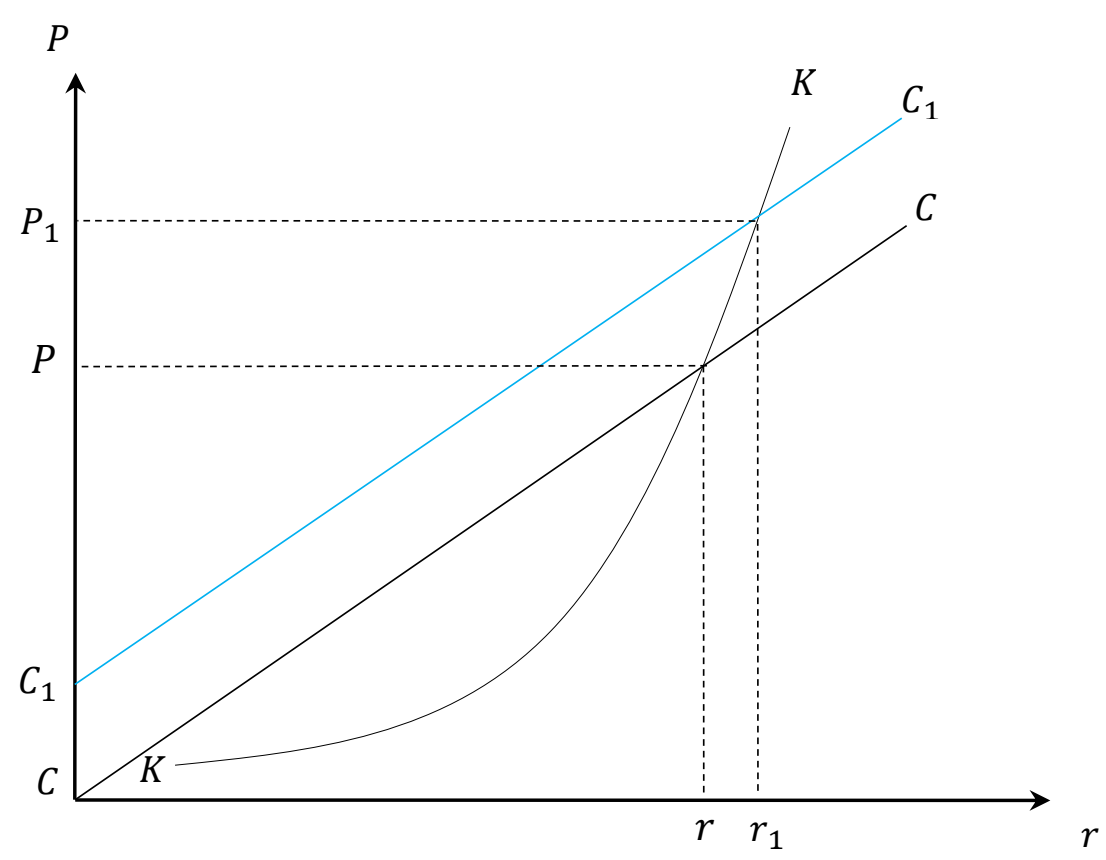

Figure 7: Product Market Imperfection and the General Equilibrium under autarky

Lower $\epsilon$ will shift up $C C$ leading to higher $P$ and $r$. It will reduce $X(\tilde{z})$ and imply a possible trade pattern where $X$ will be imported and capital will flow in. Trade in $X$ will force $P$ to be lower and $r$ to be lower as well reducing the need for capital inflow. Thus, trade in goods and capital will be substitutes, the conventional result.

Since $x(z)<k(z)(1+\beta)$, one could impute $\lambda(z)$ (where $0<\lambda(z)<1$ ) in calculation of the profit maximizing output and have $\lambda(z) k(z)(1+\beta)=x(z)$. Thus, $(1-\lambda(z)) k(z)(1+\beta)$ is the amount of wealth that could be redistributed without affecting production for $z \in[\tilde{z}, 1]$. It could either keep the production unchanged if it is redistributed towards the bottom of the wealth distribution or it will increase output, thus ruling out inefficient redistribution.

This leads us to Proposition 3.

Proposition 3: Lower degree of product market competition will increase $r$ in autarky leading to a lower chance of capital flight and is likely to prevent inefficient redistribution.

Proof: See the discussion above. $Q \boldsymbol{E E D}$. 


\section{Conclusion}

The purpose of this work is to relate wealth re/distribution to capital flows. In particular, we point out that egalitarian redistribution might not be helpful in creating entrepreneurs and hence will dampen both the demand for credit and hence the return to capital. Thus, a country may import the credit intensive good and export capital at the same time. Low autarkic price of asset or capital in our model is caused by lack of demand for capital by the entrepreneurs. Thus, lower return to capital can be an outcome of lack of entrepreneurs under autarky.

People with little wealth cannot be entrepreneurs unless their wealth level crosses a threshold. When wealth is redistributed from the rich to poor and the distribution is made more egalitarian, that threshold might not be crossed by the beneficiaries of distribution. Hence while output suffers because the existing entrepreneurs lose wealth, the receivers do not become entrepreneurs. This leads to many interesting outcomes in terms of trade and capital flows, while credit using sector produces lower output, given a chance, capital may flow out of the country because there are not sufficient entrepreneurs. Scarcity of capital may not get reflected in higher price of capital. Trade and capital flow may not get reflected in higher price of capital. Trade and capital flow become complements.

Future extension could involve the inclusion of the informal credit market into the analysis. It would enhance the availability of credit in two ways: (a) through an additional source of capital and (b) better loan monitoring. Through both the ways the informal sector would encourage entrepreneurs and increase the return on capital. Other possible extensions include the study of dynamic evolution of trade, investment, growth and entrepreneurship. One can also look at how trade will affect institutional change and will have impact on trade and capital flows.

\section{Appendix 1: Distribution and Capital Flight}

(i). We have defined $C C$ and $K K$ as follows.

$$
\begin{aligned}
& P=\phi(r, \eta) \\
& r=\psi(P, \eta)
\end{aligned}
$$

where $\phi_{r}>0, \psi_{p}>0, \phi_{\eta}>0, \psi_{\eta}<0, \eta$ represents a measure of the degree of egalitarian distribution relative to the benchmark case. Since we are focussing on the inefficient outcome we sign the derivatives appropriately. $\phi_{\eta}$ and $\psi_{\eta}$ denote the change in $P$ (given $r$ ) and $r$ (given 
$P$ ), due to an increase in $\eta$. We have deliberately suppressed other parameters in the arguments of $\phi($.$) and \phi($.$) to focus only on the relationship between trade and capital flow on one hand$ and $\eta$ on the other.

We now solve for $\frac{d P}{d \eta}$ and $\frac{d r}{d \eta}$. From (1A) and (2A)

$$
\frac{d P}{d \eta}=\frac{\phi_{\eta}+\psi_{\eta} \phi_{r}}{D}
$$

and

$$
\frac{d r}{d \eta}=\frac{\psi_{\eta}+\psi_{p} \phi_{\eta}}{D}
$$

where $D=1-\phi_{r} \psi_{p} \quad(5 \mathrm{~A})$

(ii). Note that stability requires

$$
\begin{aligned}
& \left.\frac{d P}{d r}\right|_{c c}<\left.\frac{d P}{d r}\right|_{k k} \\
\Rightarrow & \phi_{r}<\frac{1}{\psi_{p}}
\end{aligned}
$$

Or,

$$
1-\phi_{r} \psi_{p}>0=D
$$

(iii). For $P_{1}>P_{2}, r_{1}<r_{2}$ we require $\frac{d P}{d \eta}>0$ and $\frac{d r}{d \eta}<0$.

This implies $\phi_{\eta}>-\psi_{\eta} \phi_{r}$ and $\phi_{\eta}<-\frac{\psi_{\eta}}{\psi_{p}}$

Or,

$$
\phi_{r}<\phi_{\eta}<\frac{1}{\psi_{p}}
$$

Since $\left(1-\phi_{r} \psi_{p}\right)>0 \exists \phi_{\eta}$ satisfying (8A). This completes the proof of Proposition1.

\section{Appendix 2: Imperfect Product Market and Capital Flight}

$$
P=\phi(r, \eta, \epsilon)
$$




$$
r=\psi(P, \eta)
$$

Given $\eta$, now $\epsilon$ affects $P$ and through $P, r$ is affected.

Pursuing similarly as above

$$
\begin{aligned}
& \frac{d P}{d \epsilon}=\frac{\phi_{\epsilon}}{D} \\
& \frac{d r}{d \epsilon}=\frac{\psi_{P} \phi_{\epsilon}}{D}
\end{aligned}
$$

As $\phi_{\epsilon}<0 \frac{d P}{d \epsilon}<0, \frac{d r}{d \epsilon}<0$.

Thus a drop in $\epsilon$ will raise $P$ and $r$. Also profit maximising optimal $x(z) \forall z \in[\tilde{z}, 1]$ will be less than competitive $x(z)$, i.e.,

$$
x(z)=(1+\beta) k(z)
$$

Now restricting $x(z)$, they can raise $P$ and hence the premium $(P-R)$. Note that $P$ is the autarkic price. For $x(z)<(1+\beta) k(z)$, a $r(z)$ will always exist for efficient redistribution. Analytically from the definition of $\eta$ which now represents egalitarian distribution which is efficient, leading to greater output of $X$ and greater demand for $k$ with $\psi_{\eta}>0$. Note that it is not likely to change $P$ if $\epsilon$ remains unchanged. Therefore, $\phi_{\eta}=0$

$$
P=\phi(r, \epsilon)
$$

Hence,

$$
\begin{aligned}
& \frac{d r}{d \eta}=\frac{\psi_{\eta}}{D}>0 \\
& \frac{d p}{d \eta}=\frac{\phi_{r} \psi_{\eta}}{D}>0
\end{aligned}
$$

\section{References:}

Alfaro, L., Kalemli-Ozcan, S., \& Volosovych, V. (2008). Why doesn't capital flow from rich to poor countries? An empirical investigation. The Review of Economics and Statistics, 90(2), 347-368.

Antras, P., \& Caballero, R. J. (2009). Trade and capital flows: A financial frictions perspective. Journal of Political Economy, 117(4), 701-744. 
Bandyopadhyay, S., Marjit, S., \& Yang, L. (2014). International oligopoly, barriers to outsourcing and domestic employment. Canadian Journal of Economics/Revue canadienne d'économique, 47(4), 1372-1386.

Banerjee, A. V., \& Newman, A. F. (1993). Occupational choice and the process of development. Journal of Political Economy, 101(2), 274-298.

Foellmi, R., \& Oechslin, M. (2010). Market imperfections, wealth inequality, and the distribution of trade gains. Journal of International Economics, 81(1), 15-25.

Galor, O., \& Moav, O. (2004). From physical to human capital accumulation: Inequality and the process of development. The Review of Economic Studies, 71(4), 1001-1026.

Galor, O., \& Zeira, J. (1993). Income distribution and macroeconomics. The Review of Economic Studies, 60(1), 35-52.

Jones, R. W., \& Marjit, S. (2001). The role of international fragmentation in the development process. American Economic Review, 91(2), 363-366.

Lucas, R. E. (1990). Why doesn't capital flow from rich to poor countries? American Economic Review, 80(2), 92-96.

Manova, K., \& Yu, Z. (2014). Firms and credit constraints along the global value chain: processing trade in China. Working Paper No. 522, Stanford Centre for International Development.

Matsuyama, K. (2007). Credit traps and credit cycles. American Economic Review, 97(1), 503 516.

Peters, K., \& Schnitzer, M. (2015). Trade liberalization and credit constraints: Why opening up may fail to promote convergence. Canadian Journal of Economics/Revue canadienne d'économique, 48(3), 1099-1119.

Rajan, R \& Zingales, L. (1998). Financial Dependence and Growth. American Economic Review, 88(3), 559-586.

Von Hagen, J., \& Zhang, H. (2014). Financial development, international capital flows, and aggregate output. Journal of Development Economics, 106, 66-77.

Wynne, J. (2005). Wealth as a Determinant of Comparative Advantage. American Economic Review, 95(1), 226-254. 